\title{
The US 2020 Election and Learning from History*
}

Adam Przeworski

Department of Politics, New York University

\begin{abstract}
The US 2020 presidential election constitutes an anomaly for the general paradigm of learning from history that organizes cross-national research in politics. Was it a unique event that can be ignored or must we consider that history is no longer a reliable guide?
\end{abstract}

*To appear in the special issue of Studja Socjologiczno-Polityczne (Warsaw) dedicated to Jerzy J. Wiatr. I appreciate comments by John Ferejohn, Molly Przeworski, Julio Saguir, Ye Wang, and Tianyang Xi. 


\section{Introduction}

The history of science is punctuated by anomalies. From time to time, well entrenched paradigms are confronted with an event which in their light is impossible or at least highly improbable. Each time, the question arises whether such an event should be dismissed as unique, not affecting future predictions, or the reigning paradigm should be put in question.

The 2020 presidential election in the United States constitutes such an anomaly for the paradigm that organizes cross-national research on politics. In this conceptual framework we learn from history. We use the facts we have observed, which by construction are events that have already occurred, to make inferences about events not yet observed. To provide an example which is the focus of this paper, we observe whether past partisan alternations in office have followed pre-established rules, learn that alternation peaceful were more likely to be peaceful in wealthier countries, we offer causal mechanisms that would generate the observed pattern, and use this knowledge to form beliefs about events that have not yet occurred. This is what learning from history is (King and Zeng 2006, 2007).

The evidence that the U.S. 2020 election constitutes an anomaly depends on how one views and classifies this event. When the probability that a democracy falls or that an election is followed by major constitutional irregularities is conditioned either on per capita income or on the number of past peaceful alternations in office in a country, this probability is in the order of 1 in one billion. But what transpired in the US is only that the loser did not accept the result and the alternation in office was accompanied by some violence. We have no systematic data about similar events but a casual inspection of history shows that no such event has ever occurred in a well entrenched democracy. Hence, this election was a historically unprecedented surprise.

Confronted with this surprise, we must judge whether the event in question is unique, unrepeatable under the full scope of conceivable circumstances, or it suggests that our entire knowledge of the past is conditioned on some circumstances which our model ignores. If the former, the anomaly can be safely ignored; if the latter, the model must be revised or perhaps entirely abandoned.

In what follows, I first summarize our knowledge about outcomes of elections, showing that it consists of regularities that are highly robust. I then highlight conditions that render the United States highly exceptional. With this background, I confront the question at hand: What conclusions about the general framework of learning from history should we draw from the United States experience? 


\section{Outcomes of Elections}

Probably the largest body of cross-national research concerns determinants of the stability and breakdowns of political regimes. In these studies, political regimes are first either classified into discrete categories or assigned continuous scores and then changes of these indices are subjected to statistical analyses. Both the movements toward and away from democracy have been extensively analyzed but I focus here only on the stability of democratic regimes.

The variety of factors considered is large but in my view only two, perhaps two and a half, determinants of democratic stability are robust to regime classifications, data coverage, and statistical methods. The two are per capita income and the past political history of a country. The half is income inequality, which suffers from the poor quality of the data.

Writing in 1997, Przeworski and Limongi observed that no democracy ever fell in a country with a per capita income higher than that of Argentina in 1976. Since then there have been 40 democracies with incomes higher than that of Argentina in 1976 which together lived during about 1300 years and the only one that collapsed at an income just slightly higher than the Argentine one was in Thailand in $2014 .^{1}$

The general pattern is extremely clear and robust. Except for India, the probability of democratic breakdown falls steeply in income and converges to zero, with a very tight fit. Moreover, the importance of income is not diminished by introducing other factors (Benhabib and Przeworski 2006). Figure 1 illustrates the evidence:

\footnotetext{
${ }^{1}$ Venezuela may be another case but the views whether Venezuela is still a democracy and if not when did democracy collapsed vary greatly.
} 


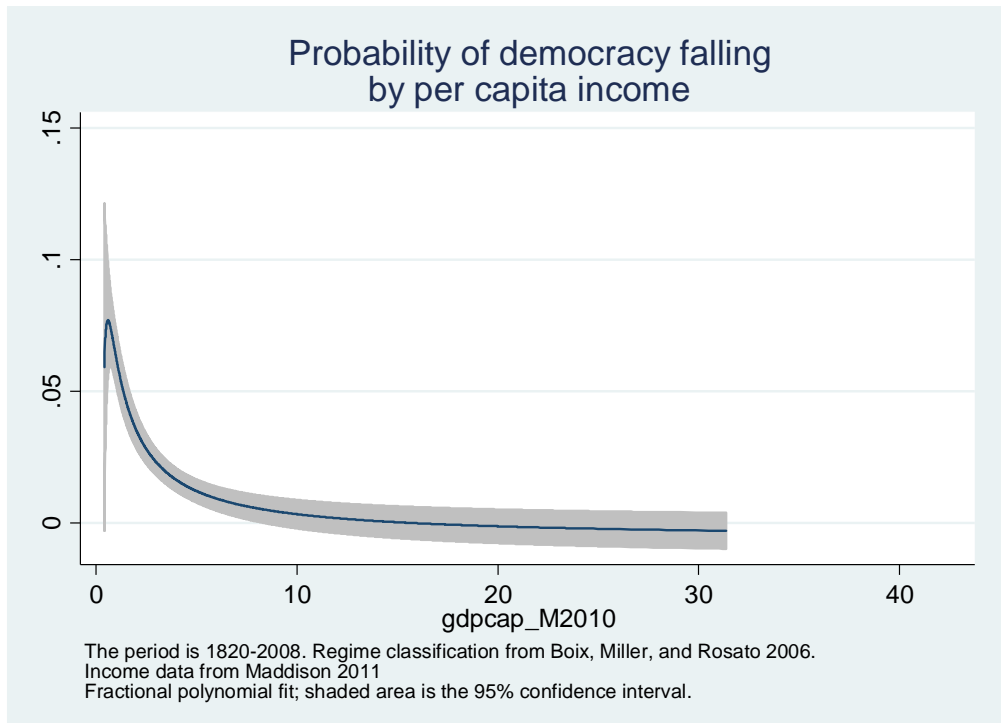

Figure 1

Democracy did not collapse in the United States in 2020, so these patterns speak only indirectly to the question whether what did transpire was an anomaly for the general conceptual framework. To bring the analysis closer the U.S., we can observe whether elections were followed by major irregularities of two kinds: either that the winner of an election did not assume office or that he/she took office but did not complete the electoral term. We learn immediately that the pattern of electoral irregularities is almost identical to the pattern of outright breakdowns:

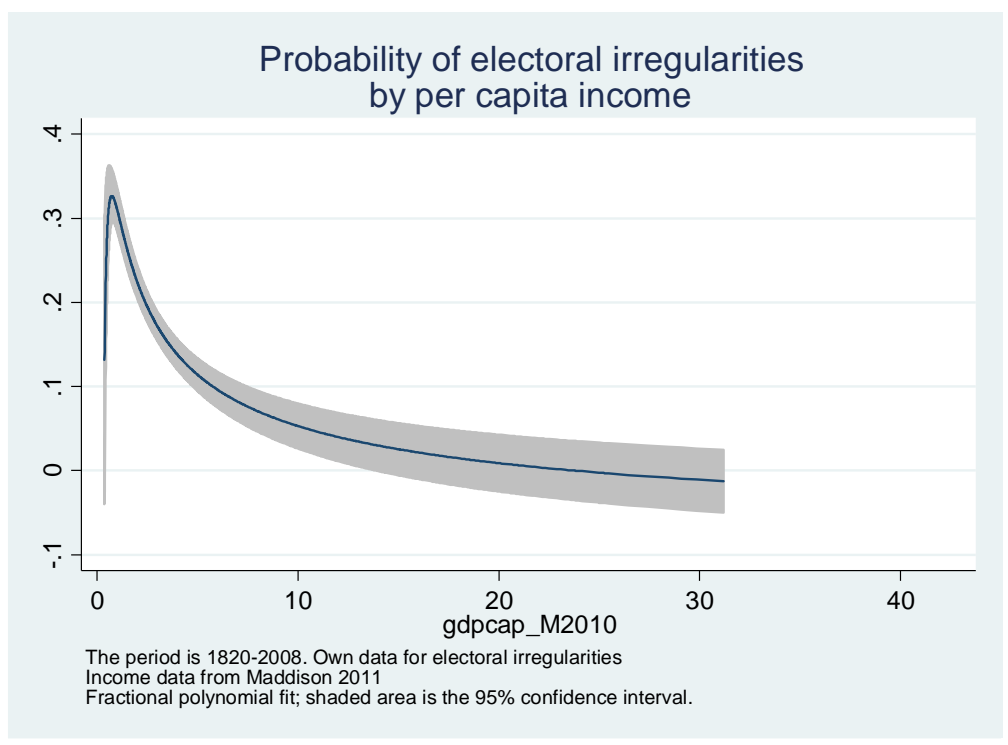

Figure 2 
The second finding which is robust is the role of past political history. Democracies that have been around for a longer time are more likely to be around. There is clear evidence that the electoral process is less likely to break down in countries that experienced more partisan alternations in office in the past. Table 1, from Przeworski (2015), shows the number of spells with a given number of past alternations, the number that was censored, the number of spells that ended in a constitutional breakdown, and the probability that an electoral spell would be broken at any time, all as a function of the number of past alternations.

Table 1: The probability of constitutional breakdown given the number of past alternations within a spell

\begin{tabular}{|r|r|r|r|r|}
\hline Past Alternations & Spells with & Censored & Broke & Pr(broke $^{a}$ \\
\hline 0 & 423 & 53 & 214 & $\mathbf{0 . 5 1}$ \\
\hline 1 & 156 & 27 & 26 & $\mathbf{0 . 1 8}$ \\
\hline 2 & 102 & 17 & 13 & $\mathbf{0 . 1 3}$ \\
\hline 3 & 72 & 25 & 5 & $\mathbf{0 . 0 7}$ \\
\hline 4 & 42 & 10 & 4 & $\mathbf{0 . 1 0}$ \\
\hline 5 & 28 & 4 & 1 & $\mathbf{0 . 0 4}$ \\
\hline 6 & 23 & 4 & 1 & $\mathbf{0 . 0 4}$ \\
\hline$>6$ & 18 & 18 & 0 & $\mathbf{0 . 0 0}$ \\
\hline
\end{tabular}

Note: The period covered is 1820-2008. Spells are periods within a country in which elections followed rules without interruptions. Hence, a country may have had several spells. All spells, including those in which alternation occurs in the first election within the spell, are considered to have began with zero past alternations. Thus 423 is the total number of spells. $a \operatorname{Pr}($ broke) $=$ Number of spells that ended unconstitutionally/Number of spells with a given number of past alternations.

The probability that the electoral process would cease to function declines rapidly in the number of past alternations, dropping to zero when a spell witnessed more than six past alternations.

Probit regressions of breakdowns on the number of past alternations within the particular spell, the electoral history of the country, and per capita income confirm that past alternations increase the likelihood that the spell would continue.

Table 2: Explaining constitutional breakdowns ${ }^{a}$ 


\begin{tabular}{|c|c|c|}
\hline Variable & effect $^{b}$ & $95 \%$ conf.int. \\
\hline sum past alt & $-0.001^{* *}$ & $-0.003,0.0000$ \\
\hline electoral spell & $0.002^{* * *}$ & $0.001,0.002$ \\
\hline gdpcap & $-0.000^{* * *}$ & $-0.000,-0.000$ \\
\hline N & 7301 & \\
\hline spells & 292 & \\
\hline lroc & 0.73 & \\
\hline
\end{tabular}

Note: Countryspell clustered errors. $a$ With cubic polynomial of electoral age, not shown. $b$ "effect" is the partial derivative or difference.

The probability that constitutionality would break down in the United States in 2020 predicted by this model is in the range of 1 in 1 billion.

These results, either with regard to collapses of democracy or breakdowns of the electoral process do not speak directly to the events surrounding the US 2020 election. Democracy did not fall in the United States and, as of now, the electoral process has not broken down. All that did happen is that the loser of the election refused to concede and that the winner assumed office under the shadow of violence: the Congress was violently invaded on the day it was supposed to ratify the results and the inauguration of the new president was witnessed by a few hundred officials surrounded by 40,000 troops. Such events are not systematically recorded across countries and time, so we cannot attach a probability to them. Yet what did happen in the United States is still sufficiently improbable to warrant considering it as an anomaly: no such event is to be found in democracies with high per capita income and a long history of past peaceful alternations in office. And even if democracy did not collapse, the question stands: what should we think about the general approach if it had? Would we conclude that the US is exceptional or would we consider it as a warning against learning from history?

\section{United States Exceptionalism}

The United States has a long tradition of claiming that it is an exceptional country. It is.

It is the only presidential system in the world in which elections are indirect. Because the numbers of the electors who cast the votes for the president are not proportionate to the population of particular states, someone can be elected with a minority of popular vote. In recent times, this occurred in 2000 and by a large margin in 2016, when the losing candidate obtained 2.8 million more votes than the winner and the outcome of the elections hinged on about 70 thousand votes. 
It is the only country in the world in which the rules of national elections vary across subnational jurisdictions.

It is a country in which the rules determining who won the election are indecisive and unclear. These rules were set in the Constitution of 1789 and amended by the 12 th Amendment in 1804. They turned out to be insufficiently clear to determine the winner of the election in 1876 and the decision was not made according to any pre-established rules. To refine them, the Congress passed a new law in 1887 and since then several modifications have been introduced in the United States Code of Law. Yet the rules remain incomplete, self-contradictory, and opaque. According to the 12th Amendment, state legislatures can choose the electors in any manner they wish and yet the current law requires the list of electors to be certified by governors of each state. As a result, the states may end up sending to the Congress multiple slates of electors and the House of Representatives and the Senate may disagree which of these slates are valid. If everything else fails, the winner is to be decided by the newly elected House, with each state having one vote. To be valid, its decision requires a quorum and current rules do not specify what should happen when there is no quorum or if there is a tie. Additional details are either not specified or not clear.

Finally, it is the only country I know in which winners of elections are proclaimed by private organizations. Ever since 1848 the winner was announced by the Associated Press, a cooperative of newspapers and broadcasters. In recent years private television networks tried to beat the AP by calling outcomes of elections first. These announcements precede the official declaration of the result by several weeks. The traditional sequence of events has been that the private media would forecast the winner, the announced loser would make a concession declaration, and the candidate designated as the winner would be recognized as the "President-Elect," until he would assume office on January 20 of the following year.

The institutional system regulating elections in the United States is unique and the rules concerning both voting and counting are exceptionally unclear. Yet this system has worked with only few major glitches during 220 years. Since 1800 there were twenty-two instances in which the incumbent party lost a presidential election and the winner peacefully assumed office. The first defeat of an incumbent government occurred in 1800 and although the country was brought to the brink of a civil war, Thomas Jefferson peacefully assumed office. A profound crisis erupted in 1876 but it was peacefully resolved by a compromise. The second emerged in 2000, when the outcome hinged on determining whether holes in a few hundred of voting cards could be read to detect 
voters' intentions and the Supreme Court, appointed in part by the father of the eventual winner, usurped the prerogative of deciding. Yet the candidate designated by the Court as the loser respected the verdict and conceded before the winner would be officially declared by the Congress. Hence, the institutional features cannot account for the crisis of the 2020 election, the result of which was not even close: the margin was 7 million votes. The explanation must reside in something else or at least the combination of the institutions with something else.

The obvious candidate for this something else is polarization. While systematic data comparing different aspects of polarization across time and space are rare and only recent, whatever we do know indicates that polarization has dramatically increased in the U.S. over the past decades and that it is exceptionally high in comparison to other countries.

When thinking about the intensity of political divisions, we need to consider two distinct aspects: (1) Distributions of preferences over some general policy dimension (liberal-conservative in the United States, leftright in Europe) or over specific issues, such as immigration. A population is "polarized" if individual preferences divide people into clusters that are internally homogeneous and distant from each other (Esteban and Ray 1994). (2) The postures that people with particular preferences hold with regard to members of other group(s). This is important because people with the same ideological profile may have different postures towards those with whom they disagree and may be willing or not to engage in hostile acts against them.

The ideological distance of party supporters in the United States, portrayed in Figure 3, has sharply increased in the past years:

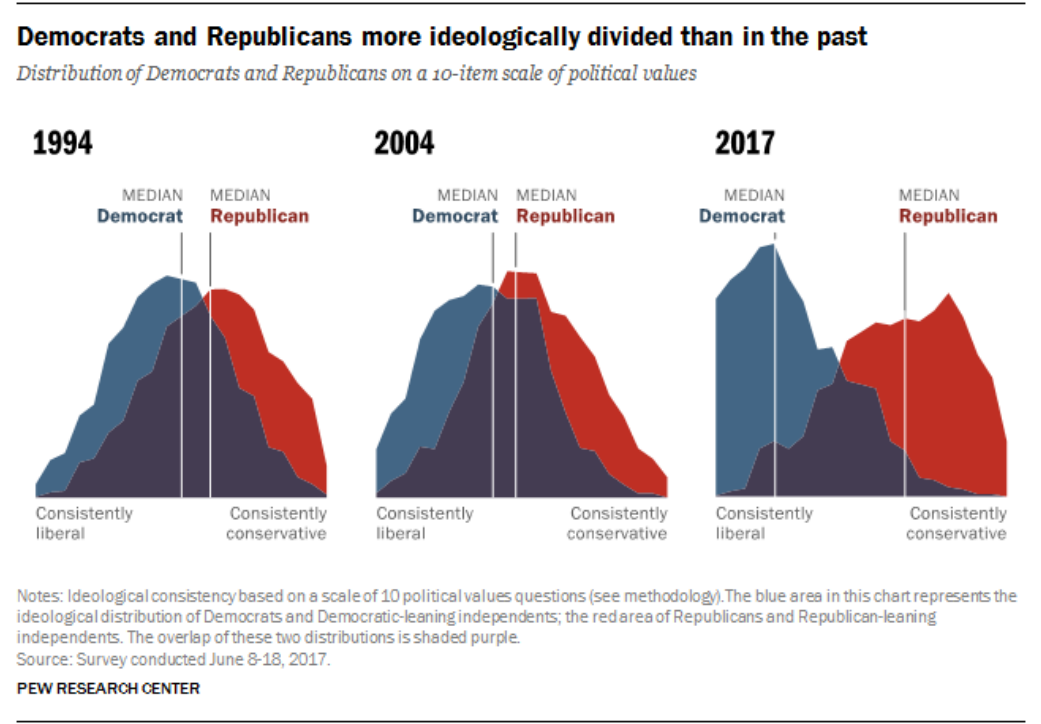


Figure 3

Even when views of particular individuals remain fixed, their attitudes toward those with whom they disagree can be less or more hostile. In the United States, 86 percent of Democrats and 91 percent of Republicans have unfavorable views of the other party, with 41 percent of Democrats and 45 percent of Republicans seeing the other party as a "threat to the nation." (Joel Acherbach and Scott Clement, "America really is more divided than ever," Washington Post, July 16, 2016.). Poignant anecdotes about experiences of discrimination and abuse in everyday life abound and many systematic data indicate that the general level of anger and hostility is on the rise. In 2012, 33 percent of Democrats and 43 percent of Republicans described themselves as angry at the opposing party's presidential candidate "most of the time" or "just about always," while by 2016, the percentage of Democratic voters who said they were this angry at Trump rose to 73 percent, and the percentage of Republicans with that level of hostility toward Hillary Clinton increased to 66 percent. Data collected by Dartman (2021) show that hostility toward supporters of other parties increased from about 50 to 75 percent in the United States between 1980 and 2016. During the same period, it did increase somewhat in Switzerland, Great Britain, Canada, and Australia but it declined in New Zealand, Sweden, Norway,

and Germany. The current level of partisan hostility in the U.S. is well above other countries for which the data are available.

Partisan hostility penetrated even into family relations. In 1960, 5 percent of Republican sympathizers and 4 percent of Democratic ones would have been displeased if their offspring were to marry across party lines, while in 2010 these percentages were 49 for Republicans and 33 for Democrats. In 2017 a Thanksgiving dinner with guests from electoral districts dominated by different parties lasted 30-50 minutes less than with exclusively co-partisans (The average was 257 minutes; Chen and Rohla 2018).

To summarize, while it is impossible to assess whether the current level of partisan hostility in the U.S. is historically unprecedented, scattered pieces of the available evidence indicate they it is exceptionally high.

\section{Learning from History}

With this background, we can approach the central issue we face. The validity of the paradigm of learning from history depends on how likely an anomaly observed is to reoccur. If the conjuncture of conditions that 
emerged in the U.S. in 2020 is unique, we can dismiss it: unique means that it would not be repeated anywhere else at any time or at least that its probability of occurring vanishingly small. But if there are grounds to believe that the encountered anomaly is a harbinger announcing new historical conditions, then the entire undertaking of learning from history ceases to be a reliable guide to the future.

King and Zeng (2005) argue that learning from history is less reliable for new observations that deviate far from the previously observed conditions. This is not the situation we face with regard to the US election. Figure 4 portrays the values of per capita income and the numbers of past alternations for the data set on which the findings presented above are based. The time span ends in 2008 but the value of these factors for the US in 2020 would be located in close proximity to the observed set. This figure also shows the isoquant line above which the probability that a democracy would fall is lower than 1 in 1 billion, and the US in 2020 lies even farther above it than the observed values. ${ }^{2}$

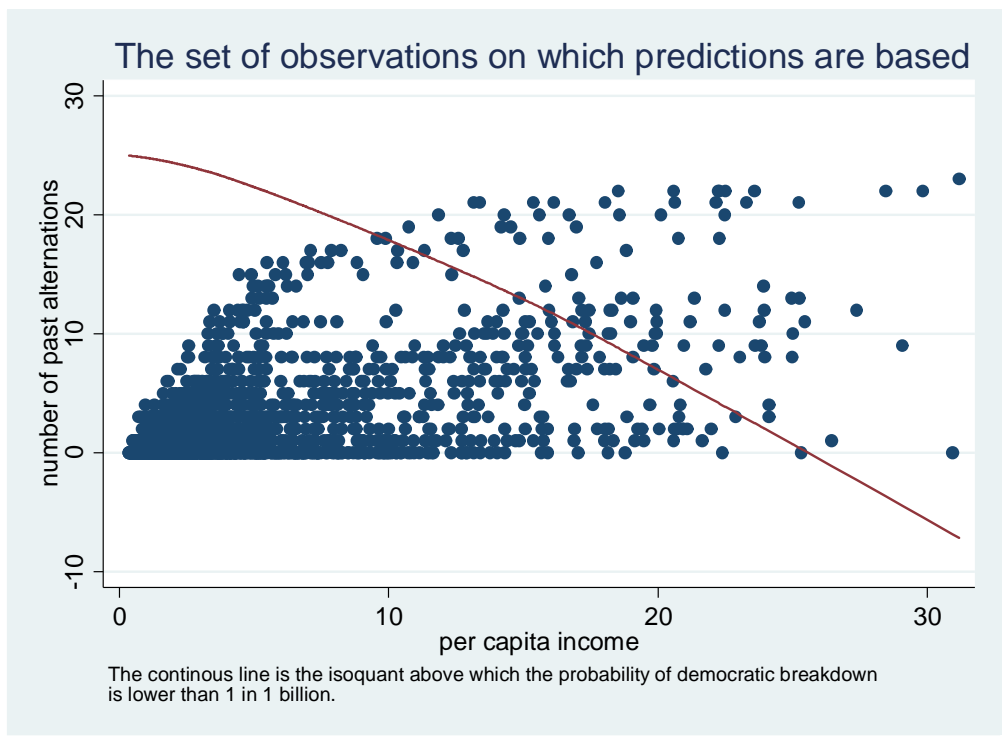

Figure 4

Proximity to past observations, however, is not sufficient to guarantee the validity of inductive inferences. The factors that determine the outcome may have predictive power only within some neighborhood and their effects may change discontinuously at the border of this space.

\footnotetext{
${ }^{2}$ Note, by the way, that while collapses of democracy are rare, there are 77 elections in the observed set for which the probability of collapse was higher than 1 in 10 elections. Obviously, there are located in a left lower corner.
} 
An obvious example is climate change, in which the servo-mechanism that moderates the temperature may break down when the temperature reaches some upper level. Hence, inferences based on thousands of years of observations may become invalid when the temperature reaches some "tipping point."

Another possibility is that the set of the relevant conditions contains some factors omitted from the model, which either alone or in combination with other factors affect the outcomes. There are good theoretical reasons to think that polarization should affect the decision of competing parties to respect the outcomes of elections. Przeworski, Rivera, and Xi (2015) have shown that results of elections are respected when the stakes in elections - the difference of the value of winning and losing them - is neither too small nor too large. When outcomes of elections make no difference, it does not matter who governs, so the losing party can claim victory without encountering costly resistance from the winning one. When the outcomes make a huge difference, the losers resist obeying them even at the cost of generating costly conflicts. High polarization means either that the difference between the platforms of the parties is large, or that even small programmatic differences are experienced by party leaders and supporters as large, or both. ${ }^{3}$ For example, some people experience any deviation from their ideal point on abortion policies as intolerable.

Just as an illustration - without any claims about its truth - imagine that polarization does not affect whether elections are peaceful for as long as per capita income remains with some range but once material prosperity crosses some critical threshold, cultural conflicts dominate economic ones and the country enters into a realm where political conflicts are difficult, if not impossible, to resolve peacefully. In the Przeworski, Rivera, Xi (2015) model this occurs when the difference between the present values of winning and losing an election exceeds the cost of entering into a violent conflict. The mechanism would be that, in accordance with the "post-materalist" theory (Ingelhart 2018), the salience of cultural aspects becomes more pronounced as material needs are being satisfied but, contrary to this theory, cultural conflicts generate intense conflicts. Whatever "traditional" may mean in a particular society, many people feel that their traditional way of life is under a mortal threat. Whether it is religion, ethnic purity, gender relations, or

\footnotetext{
${ }^{3}$ In a classical paper, Estaban and Ray (1994) define polarization in terms of the distance of ideal points. But the new work on "affective polarization" shows that people may perceive a large loss even when an outcome does not deviate much from their ideal point. One way to think about polarization is that includes both distances between ideal points and the slopes of utility functions around them.
} 
family structure that provides the ideological linchpin to the resistance, the resistance is fierce. It may be more acute where the cultural and demographic transformations have been more rapid ${ }^{4}$ : in some countries immigration, in some the LGBTQ movement ("genderism" was seen as the greatest threat to Poland by a plurality of respondents in 2018), in some the rise of new household structures. In the U.S., for example, there is a pronounced difference in voting patterns between people who are married and those who are single: In 2020, 54\% of married voters voted for Trump and $57 \%$ of not married ones for Biden. The difference is even larger among women. (https://news.virginia.edu/content/whatexit-polls-are-telling-us). We should then expect that the probability of collapses of democracy steeply increases when political polarization is high, and polarization is not a factor included when we draw lessons from history because within the range of conditions observed in the past it was not decisive.

Polarization is plausibly the hidden condition that generated the U.S. anomaly. But it may have been polarization in combination with other factors or not polarization at all. Our model is silent about it.

Now, there are all kinds of vague signs that the world has changed over the past couple of decades (Przeworski 2019). Their list includes the collapse of several traditional party systems, the emergence of radical right parties and leaders, declining popular confidence in all kinds of institutions and in the people who populate them, increased polarization over some issues and increased partisan hostility, large and growing economic inequality, an erosion of beliefs in intergenerational material advancement, ...; the list is long. None of these phenomena are universal, with large variations across countries. Issue polarization, for example, increased in some countries and declined in others (Medina 2015). But there are some aspects of the U.S. situation that seem to be present in other countries: Brazil, India, Hungary, Peru, Poland, Turkey, Venezuela are among them.

Two among these aspects merit speculating about. First, back to polarization. While causal identification seems impossible, there is observational evidence that cultural issues divide societies independently of economic factors. The change of the relation between positions people take on particular issues and their partisan preferences may amount to being epistemological (Lewandowsky, Ecker, and Cook 2017). In our standard way of thinking, people have positions of particular issues, parties make proposal and offer candidates, and people support parties and candidates to whom they are closer. Causality runs from individual pref-

\footnotetext{
${ }^{4}$ I owe this suggestion to Fernando Rosenblatt.
} 
erences to partisan choices. But, at least in the U.S. it appears that the causality now runs the other way: from partisan loyalties to issue positions. The almost instantaneous shift of the Republican Party from the ideological commitment to free trade to its opposition to globalization is just unfathomable. We even have a new term of cognitive psychology: "partisan motivated reasoning." People process information and organize their worldview according to their partisan loyalties.

The second recent transformation is of the technology leaders use to remain in power. In the past, autocratic leaders had to kill many people: think of Stalin's purges or the Tiananmen Square massacre. Now the technology is subtle, obfuscating the difference between different regimes. When Alvarez et al (1996) dichotomously classified political regimes as democracies and dictatorships, there was just a handful of country-year cases that resisted being clearly qualified by a few criteria, most of them from Botswana. But it became gradually clear that the number of cases that escape the dichotomy was increasing, and we developed labels such as "hybrid regimes," (Levitsky and Way 2010), "electoral authoritarianism," and the like, denoting regimes which maintain the trappings of democracy without threatening the tenure of their leaders. Putin is a clear master of this technology. Trump tried to use it but, fortunately, he was incompetent. Now the Republicans at the states level are learning quickly how to suppress votes and control their counting. As our new vocabulary recognizes, in several countries we have witnessed instances of democratic "backsliding" (or "deconsolidation," "erosion," "retrogression"): "a process of incremental (but ultimately still substantial) decay in the three basic predicates of democracy - competitive elections, liberal rights to speech and association, and the rule of law" (Huq and Ginsburg 2018: 17). As this process advances, the opposition becomes unable to win elections or assume office if it wins while the established institutions lose their capacity to control the executive. This is a historically new phenomenon. In the past, we were able to attach precise dates to breakdowns of democracy - 31 March 1933 in Weimar Germany, 11 September 1973 in Chile - and our lessons from history are derived from observing such discrete events. Thus, we need to rethink and reconceptualize the very phenomenon about which we want to learn from history (Magaloni 2017).

Clearly, this is not an analysis that can generate conclusions. It is just a note of warning. The events surrounding the U.S. election shattered all expectations. The question is what we should expect now, once it all happened. 


\section{References}

Alvarez, Michael, José Antonio Cheibub, Fernando Limongi, and Adam Przeworski. 1996. "Classifying Political Regimes." Comparative Studies in International Development 31: 3-36.

Benhabib, Jess and Adam Przeworski. 2006. "The political economy of redistribution under democracy." Economic Theory 29: 271-290.

Chen, M. Keith, and Ryne Rohla. 2018. "The effect of partisanship and political advertising on close family ties." Science 360 (June 1): 1020-4.

Dartman, Lee. 2012. "Why the two-party system is effing up U.S. democracy." 538, June 16.

Esteban, Joan-María, and Debraj Ray. 1994. "On the Measurement of Polarization." Econometrica 62: 819-851.

Ginsburg, Tom and Aziz Z. Huq. 2018. "How to lose a constitutional democracy." UCLA Law Review 65(1): 78-169.

Inglehart, Roman. 2018. Cultural Evolution: People's Motivations Are Changing, and Reshaping the World. New York: Cambridge University Press.

Levitsky, Steve and Lucan A. Way. 2010. Competitive Authoritarianism: Hybrid Regimes After the Cold War. New York: Cambridge University Press.

Lewandowsky, Stephan, Ullrich K.H. Ecker, and John Cook. 2017. "Beyond Misinformation: Understanding and Coping with the"PostTruth" Era." Journal of Applied Research in Memory and Cognition 6: 353-369.

Magaloni, Beatrice. 2017. "Thought piece on how democracies fail." Prepared for the conference "How do Democracies Fall Apart (And could it happen here)?" held at Yale University, October 6, 2017.

Medina, Lucía. 2015. "Partisan supply and voters' positioning on the left-right scale in Europe." Party Politics 21: 775-790.

Moral, Mert, and Roben E. Best. 2018. "On the Reciprocal Relationship between Party Polarization and Citizen Polarization." Paper presented at the 2018 Annual Meeting of the Midwest Political Science Association, Chicago.

Przeworski, Adam. 2015. "Acquiring the Habit of Changing Governments through Elections." Comparative Political Studies 48: 1-29.

Przeworski, Adam. 2019. Crises of Democracy. New York: Cambridge University Press.

Przeworski, Adam, and Fernando Limongi. 1997. "Modernization: Theories and Facts." World Politics 49: 155-83.

Przeworski, Adam, Gonzalo Rivero, and Tianyang Xi. 2015. "Elections as a method of processing conflicts." European Journal of Political 
Economy 39: 235-243. 